\title{
The Impact of the Application of a Process Writing Component on the Students' Writing Output in English as a Foreign Language
}

\author{
Alexandra Anastasiadou \\ State School Advisor- Regional Directorate of Education for Central Macedonia Greece \& \\ Hellenic Open University \\ dhm3kat@yahoo.gr
}

\begin{abstract}
Various theories concerning the teaching of writing in both an L1 and an L2 have been burgeoning since 1945, given the importance of mastering the ability to write legibly, fluently and coherently for the students' academic success. The aim of this paper is to delve into young learners' performance influenced by the applicability of the "process writing" approach in learning English as a foreign language and the same time to trace any gender differences. More specifically, a study was conducted at the sixth grade of two Greek state primary schools. The findings presented in this paper are part of a greater study which involved two experimental (44 students) and two control (46 students) groups.

The two experimental groups of the study attended seven specially designed writing lessons, whereas the control group members followed the materials of the coursebook. Both groups were given similar written assignments in order to receive comparable results. Entry and exit writing tests were administered to the participants of the study in order to explore their performance in the beginning and the end of the research and trace any differences due to the intervention, regarding both group and gender.

The analysis of the group and gender parameters shows that there is change of performance between the two groups and genders.
\end{abstract}

\section{Introduction}

Eminent linguists and researchers (Kroll, 1990; Brookes \& Grundy, 1990; Grabe \& Kaplan, 1996; Tribble, 1996; O'Brien, 1999; Hyland, 2002) argue that the teaching of writing has always gathered momentum in all educational systems, and many,

(cc) BY-NC-ND 
mostly contradictory, suggestions have been worded about the best methods of teaching it. The first model concerning teaching writing, which surfaced in 1945 and prevailed until 1965, was controlled or guided writing (Pincas, 1962). Following the behaviourist approach, this model regarded writing in second language as a habit formation leading to a decontextualised text consisting of a series of sentences without any consideration for audience and purpose.

In the mid-sixties the attention shifted to the layout of the product and, thus, the product-oriented pedagogy emerged, being a text-based approach (Tribble, 1996: 37). Model texts were introduced to students who were required to unquestionably apply their organisation to a similar piece of writing without any previous experimentation with their layout. In this light, writing was seen as simply imitation of input (Badger $\&$ White, 2000) without any active involvement of the students in the formation of the written text.

In the early seventies, the process-approach (Taylor, 1981; Zamel, 1982; Raimes, 1983) refuted the linearity and excessive concern with form and predetermined patterns of the previous paradigms of teaching writing. Writing is a recursive problem-solving process to discover meaning. By no means does this emphasis on process indicate negligence of form, though. Hedge (1994: 2) claims that "process writing" takes equal consideration of both the form and the procedure, taking into account the students' level and needs for writing, at the same time. Later other theorists like (Hedge, 1988; Byrne, 1988; and White \& Arndt, 1991) elaborated more on the method, keeping its creative thinking aspect but also stressing other significant traits such as the purpose and audience, context and collaboration among the students and between the teacher and the students embedding, therefore, the interactive and social angles in writing. Finally, White \& Arndt (1991) focused on the experimentation with the characteristics of various text types.

The latest important approach to teaching writing is the genre approach (Hyland, 2002), the main tenet of which is to demand that the learners consciously discover and apply the rules of the written product, which varies according to the social context, where it is communicated. Every text type complies with the conventions of a recognisable generic type, takes into consideration the target audience and assumes that the content and layout of a piece of writing should pertain to a social purpose. The genre approach evoked criticism which was explicitly articulated by Harbord (2005: 5) who supports the view that this paradigm "is inherently prone to prescription" contradicting, thus, the assumptions of the learner-centred teaching. Another weak point is that it downgrades the cognitive struggle the writers go through while producing a text.

In this paper the use of the "process approach" was selected as the most suitable pedagogy with the aim of empowering students to become familiar with the process of organising various texts and simultaneously obtain transferrable skills being, in this way, aided in their future writings. 


\subsection{Description of the Process-Oriented Pedagogy}

Having prioritised process writing as the appropriate approach for teaching writing, an effort will be made in this section to present its underlying philosophy and stages, and suggest a proposed model. This paradigm stresses the process without neglecting the product, though, supplying the students with the opportunity to ameliorate their writing capacity.

As early as 1971 Emig identified five stages of the composing procedure in the process approach: (a) prewriting (being motivated to write, generating ideas, outlining and rehearsing, making notes), (b) drafting (writing in progress individually or in collaboration), (c) revision (replanning, adjusting according to readers, and redrafting after receiving peer or teacher comments), (d) editing (getting ready for publishing the written text), and (e) publication (sharing the product with the public).

During the whole process, the writers tend to their audience, the purpose of writing, the topic requirements, the generic type of the text and the social situation whereby writing is presented. Even though it could be corroborated that the elements of establishing the social context of a piece of writing and experimenting with the layout of different text types have been informed by the genre approach, these two vital issues were fully incorporated in the process writing philosophy by White \& Arndt (1991). Thus, "process writing" has been developed to operate in an extended context, having assimilated vital elements of the genre approach.

In this light, the present writer proposed a framework for process writing which indicates that writing is recursive rather than linear and exhibits the relationships between the various subcomponents of writing as well as the interactions of the participating members (Figure 1 ).

The writer always bears in mind the task requirements encircling the target audience, the aim of writing, the genre of the text type, the topic specifications and the social situation within which writing is embedded. The teacher is also connected with all these elements in an effort to help the learner to fully comprehend and monitor the task specifications. Moreover, these task requirements interact with the text, in the sense that they define the layout of the constructed piece of writing.

The task specifications initiate the process of writing which is cyclical, allowing the writers to move backwards and forwards while following the above mentioned stages of process writing. This recursive process is interdependently related to the text, since the process leads to the generation of the text and the text feeds the process. Both the teacher and the writer participate in the writing process and in the generation of the text and interact during the entire endeavour. 


\section{Research Evidence on the Efficacy of "Process Writing" to Teaching Writing}

\subsection{Research on the Introduction of the Process Pedagogy in Various ESL/EFL Contexts}

Only a few studies have attempted to explore the wholesale application of the process approach to a product-oriented educational milieu. Three of these studies (Kern \& Schultz, 1992; Gallego de Blibeche, 1993; Akyel \& Kamisli, 1996) indicated positive results from the implementation of the process paradigm, namely on the students' performance and attitudes towards writing. Nevertheless, no control group was included in Kern \& Schultz (1992). Pennington et al. (1996) showed that the students' reaction to the introduction of process writing was aligned with the teachers' positive or negative preferences of the integration of the new approach. Hammouda's (2005) study revealed the necessity to fine-tune and redefine the pedagogy to fulfil different learning styles and educational traditions.

A study with disparate findings is the one by Gomez, Parker, Lara-Alecio \& Gomez (1996) seeking to investigate the effectiveness of process writing against the product-centred method with a group of low achieving English proficient (LEP) sixth grade SL students.

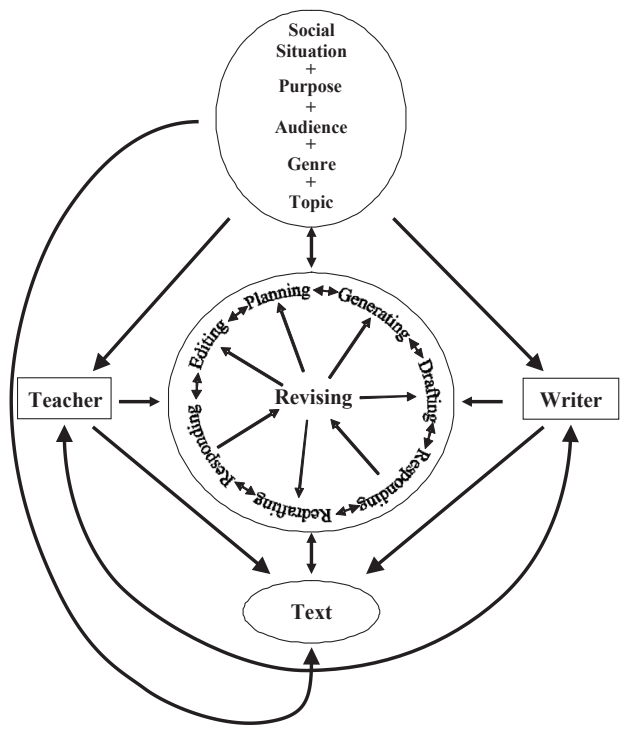

Figure 1. The proposed model of process writing (Anastasiadou, 2010) 
The process writing group gained in meaning and productivity but there were not any statistically significant differences between the two groups. On the contrary, the product writing members equalled or even outperformed in organisation their process writing counterparts. The researchers admitted that these findings may be due to the limited time span of the study.

With particular reference to Greek educational context, only a few studies have been carried out in Greece, involving early primary students (Giannakopoulou, 2002), Greek high school students (Hasiotou, 2005; Koutsogeorgopoulou, 2007; Drepanioti, 2009) or computer assisted process writing (Nikolaki, 2004; Simou, 2006; Takou, 2007), all of them demostrating beneficial effects on the students' performance and attitudes towards writing due to the application of process writing.

\subsection{Research on Gender-Related Differences}

A host of SLA studies addressed the differences between the two genders and offered evidential support that girls usually outperform boys. Two surveys regarding motivation in second/foreign language learning (Muchnick \& Wolfe, 1982; Sung \& Padilla, 1998) detected that females had significantly higher scores than their male counterparts. As far as time devoted to studying English and willingness to prepare homework are concerned, Nikolaou (2004) traced superiority of female performance over male output based on statistically significant difference.

\section{Aim and Scope of the Present Study}

The aim of the current study was to explore the application of process writing in teaching young learners in the Greek state primary school with a view to investigating any improvement in performance concerning both group and gender.

The original assumption of the present research is that it is the syllabus and the lack of active student participation in the writing process which prevents learners from developing writing ability in English. Therefore, a new syllabus was designed by the present writer for the purpose of the present research based on the "process-focused" (White \& Arndt, 1991) approach to writing, which aims to familiarise students with the process of writing and on approaches about correct learning methodologies for young learners. The current study compares the existing syllabus ${ }^{1}$ at the state primary schools, which prioritises the product of

1 The syllabus which was in effect at the time of the conduct of the research, that is 20072008, was guided by the course book FUN WAY 3. 
writing, with the experimental syllabus concentrating on the process of writing on two dimensions: 1) the performance parameter: whether the parallel syllabus will manage to improve the students' written performance, and 2) the gender parameter: whether the gender has an impact on the students' reaction to the intervention.

To this end, two research questions were addressed:

- Will the students of the experimental group of the sixth grade of state primary schools, who receive process writing tuition, outperform the students of the control group as far as the overall writing ability in English is concerned?

- Will there be any gender differences, as previous research has suggested? More specifically, will the girls of the experimental group respond more positively to this approach and present better results than the boys?

\section{Methodology and Design}

A longitudinal research was conducted lasting one school year (2007- 2008) as part of a doctoral thesis. The study was carried out in the sixth grade of two state primary schools in Katerini, a northern town in Greece exhibiting the characteristics of the majority of the state elementary schools all over Greece as far as the student population is concerned, that is, most of the students are Greek and a percentage of them belong to families who have emigrated from the countries of the former Soviet Union, Albania and Romania.

\subsection{Instrumentation}

A combination of qualitative and quantitative techniques was employed in order to "ensure greater reliability through triangulation" (Hyland, 2002: 158). The quantitative approach involved the use of

1. the reading, vocabulary and grammar sections of the Oxford Quick Placement test (2001) which is a standardised test, trialled with more than 5.000 students in 20 countries. Two versions were used to minimise the risk of cheating and determined the students' level at A2- . This level matches the classification of the Pedagogical Institute and corresponds to the lower/early Waystage level according to the Common European Framework of Reference for Languages (2001), whereby the students are basic users of a foreign language.

2. an entry writing test specified the students' writing performance in the beginning of the study, while an exit writing test of similar difficulty detected the students' writing capacity at the end of the research with a view to tracing any differentiation between the entry and exit point. 
The qualitative method consisted of the analysis of the presentation, organisation, coherence and layout of the main ideas of the students' texts both at the entry and exit point and during some writing lessons.

In an effort to formulate an efficient rating scale for the participants of this level, the CEFR was thoroughly examined. As a result, an analytic marking scheme (Appendix A) was designed providing detailed information about the students' strengths and weaknesses. The requirements of the assessing scale of Cambridge ESOL Examinations KET $(1998,2006)$ and the KPG (Dendrinos, 2007) were also consulted for the construction of the present marking scheme.

Thus, three criteria with respective sub-criteria, which evaluate both meaning and form, were singled out to be included in the analytic rating scale:

Criterion 1: Sociolinguistic Competence.

If the learner responded in terms of (a) communication of message, (b) fulfillment of required function, and (c) audience awareness.

Criterion 2: Linguistic Appropriateness.

The written text was assessed for (a) spelling, (b) punctuation, (c) grammatical accuracy, and (d) vocabulary range.

Criterion 3: Pragmatic Competence.

The written text was assessed for (a) organisation according to genre, (b) cohesion, (c) style, and (d) coherence.

Both the entry and exit writing tests were graded by two experienced raters, holders of a Master's degree specialising in the teaching and testing the four skills in English. Both raters thoroughly studied and experimented with the marking scheme with the aim of correctly and impartially implementing the predetermined criteria.

\subsection{Participants}

Four mixed proficiency classes took part in the research: two experimental (44 students) and two control (46 students). One class from each of the two schools was randomly chosen as the experimental group while the other two classes served as control groups. In Greek state schools, the students are assigned in classes alphabetically minimising, thus, the risk of selection bias.

The control group members followed the materials of the coursebook while the experimental group students attended seven writing lessons specially written by the researcher following the process writing tenets. Both groups were offered the same writing assignments so as to obtain comparable results.

The two teachers of English who taught the experimental and control groups in both schools participated in the research. These two colleagues were present during the writing sessions but it was the researcher who did the actual teaching of writing. 


\subsection{Analysis of the Collected Data}

Difficult as it may be, a qualititative analysis, which involved the comparison of the students' entry and exit writing tests and their texts during the writing lessons, was ventured based on the implemented marking scheme.

The statistical analysis was conducted using the SPSS 15.0 (SPSS Inc, Chicago, IL) and a $p$-value $<0.05$ was defined as significant. The independent samples $t$-test was employed to gauge the participants' grades according to group and gender at the beginning of the study. At the end of the research, the two-way ANOVA was preferred so as to measure not only the performance according to gender and group but also the interaction effect between the sex and the group with the aim of detecting any influence of the two variables on one another and the students' output.

\section{Findings and Discussion}

This section presents the results of the study and discusses their interpretation in an attempt to explore whether the research questions were verified in order to offer plausible explanations and to argue about the pedagogical implications of the received data.

\subsection{Qualitative Analysis}

Some pieces of writing, corresponding to the entry test and the exit test (appendix B) respectively, will be presented and discussed here, in order to trace any differences between the two groups and justify the efficacy of the intervention. The participants' writings will be provided exactly as they were worded.

\section{Experimental group \\ - Case one Student $53 \mathrm{E}$ \\ Entry text}

$$
\text { 15-10-07 }
$$

Dear George

How are you in boston? Are you OK? Here in Katerini weare all OK but the school year is beginning. How are you feeling?. Did you go for holidays? I go for holidays in Mykonos. It was really nice. I was swimming in the morning then I go for fishing with my father. How about your summer holidays? I hope see you soon. Whith love Alex (his surname- not to be provided for anonymity reasons).

Katerini 60100

P.D

I'm writing for your letter. And your dog isn't in life 
$\underline{\text { Final text }}$

60100

Greece

Katerini

19 Pythagora

\section{Dear George}

I'm really fine and very very happy because the scools will end at two weeks. but I'll loose my friends and that's something bad maybe very bad. If we go for holidays we'll go to germany with my family. There I have my cousins. I'll play ther with them. What will you do on your summer holidays? Please write me soon.

Love

Dimitris

\section{P.S. If you want come in Greece}

In the first piece of writing the three parts of the message are introduced, whereas the fourth is partly attempted (i.e. there is no address) and partly wrong (that is, he signs off with his own name and surname instead of using the name given in the instructions. Furthermore, the postscript is incoherent). There is a fairly good organisation of ideas and the text is mostly comprehensible. There are a few problematic grammatical issues, mainly wrong use of tenses.

The second text is far superior to the first one as far as structural organisation, communication of message, coherence, cohesion, ordering of ideas and audience awareness are concerned. To be more specific, all four parts of the message are sufficienty presented, the ideas are well-organised producing an intelligible text with appropriate linking words. There are some surface errors (i.e. loose, come in Greece), which do not interfere with the meaning, nonetheless.

Control group

- Case two Student $2 \mathrm{C}$

Entry text

35 Kandou St.

\section{Dear George,}

I'm sick. I feel happy because I see my friends. in school I went from holidays in Xalkidiki. There I went to swim, ate many ice-creams and bote souvenirs. There I lived two weeks.

Were were you went in summer? Haved fun? What you did there? What do their parents?

P.S. In my holidays I went in Patra, Sparty and in Athens. 
$\underline{\text { Final text }}$

Kanthou 35

T.K. 60100

20/5/08

Dear George,

How are you? I'm fine and happy, because is the last week. I play all day and go out with my friend.

I'll go with my syster and my parents to Corfu. I'll take with me lots of money I'll go swimming, I'll play beach volleyball, football and basketball. I'll travel by fery. I'll go shopping all day. I'll eat out with my parents and my sister. That's all for me.

Where you will go for holidays? Will you go to island? I wish you to be happy and excited.

$$
\text { Love }
$$

Christos

In the first piece of writing, two parts of the message are adequately presented, whereas the other two are unsuccessfully addressed (i.e. the postscript is correct but irrelevant, since in the preceding text the student mentioned having gone to Chalkidiki on holidays and then in the postscript different holiday destinations are included). The ideas are not well-organised, even though the text is generally comprehensible. Besides, the occurrence of spelling, punctuation and grammar errors is more than frequent.

The final writing displays significant improvement. Three parts of the message are explicitly introduced and one is partly addressed (i.e. there is no postscript) and partly incorrect as he signs off using his own name rather than the one given in the rubrics. There are some spelling errors with no influence on intelligibility but grammar agreement is occasionally neglected. (e.g. Where you will go for holidays?)

Brief as the qualitative analysis of the written texts as it may be, it, nevertheless, revealed that the experimental group members were trained to read the assignment rubrics carefully, follow the task specifications, try to organise and reorganise their ideas, be careful while correcting their errors, and, as a result, they were able to produce better texts than the control group participants. In other words, the experimental group outperformed the control one in all the essential levels of writing, namely, the textual, ideational and organisational.

Moreover, the interpretation of the presented written texts indicated that the experimental group students realised that writing represents a recycling, re-organisation and re-structuring of both ideas and form, rather than a linear process where the layout of the content and the structure is "a preliminary and finite stage" (White \& Arndt, 1991: 78). In this vein, it was proved that far from being susceptible to prescription, neglecting individual differences, limiting the learners' active participation, and shaping their way of thinking, as criticism (Reid, 184a, b; Horowitz, 1986; Hyland, 2002) levelled towards process writing supported, it ameliorates their creativity. 


\subsection{Quantitative Analysis}

Table 1 illustrates that no statistical significance was found between the experimental and control group at the outset of the study, consequently, it can be easily deduced that the two sample groups were homogenous presenting equal writing performance in the entry test.

Table 1.

Independent samples t-test for grades at pre-test according to group

\begin{tabular}{|l|c|c|c|c|c|}
\hline GROUP & N & Mean & SD & t - score & p (t-test) \\
\cline { 1 - 4 } CONTROL & 46 & 4.27 & 2.62 & \multirow{2}{*}{-1.365} & 0.176 \\
\cline { 1 - 4 } EXPERIMENTAL & 44 & 5.08 & 2.98 & & \\
\hline
\end{tabular}

The independent samples $t$-test which was computed to compare the differences in grades between male and female participants at the initial point of the research demonstrated the following findings:

1. The mean score of the girls is 5.45 and for the boys 3.85 irrespective of the group they belong to (Table 2 ).

2. Since significance is 0.007 , and therefore $p<0.01$, it can be concluded that the difference in performance between the two genders is statistically significant.

Table 2.

Independent samples t-test for grades at pre-test according to gender

\begin{tabular}{|l|c|c|c|c|c|}
\hline GENDER & N & Mean & SD & t - score & p (t-test) \\
\hline MALE & 44 & 3.85 & 2.70 & \multirow{2}{*}{-2.779} & \multirow{2}{*}{$0.007<0.01$} \\
\cline { 1 - 4 } FEMALE & 46 & 5.45 & 2.73 & & \\
\hline
\end{tabular}

Table 3 indicates that both the gender and the group have an impact on the students' written attainment. For the two parameters the difference was significant at 0.017 level (gender) and 0.049 level (group). This points to the fact that in the exit test the experimental group outperformed the control one with a marginal significance at 0.049 which verifies the first research question. The statistical analysis concerning the two genders shows that the girls outperformed the boys in the post-test. This numerical superiority of the girls proves that females indeed presented better results. Consequently, the second research question is substantiated on statistically significant terms. 
No statistical significance was found for the interaction between gender and group, which signifies that gender and group have affected the final score as distinct variables and as a result the efficacy of the intervention is highlighted (Table 3).

Table 3.

Two-way ANOVA results for the post-scores by gender and group (Tests of Between-Subjects Effects)

\begin{tabular}{|l|c|c|}
\hline & $F$ & $P$ \\
\hline GENDER (main effect) & 5.88 & $\mathbf{0 . 0 1 7}<0.05$ \\
\hline GROUP (main effect) & 3.98 & $\mathbf{0 . 0 4 9}<0.05$ \\
\hline GENDER by GROUP(interaction effect) & 0.229 & 0.633 \\
\hline
\end{tabular}

On the other hand, the percentage rise of the experimental group at the entry and exit point shows a parallel increase between the two genders (Figure 2). Thus, it can be deduced that the applied intervention was challenging and affected positively both genders. This issue is worth noticing since the need for further research surfaces, which will investigate whether appealing teaching approaches and challenging, well-organised materials could lead to similar results in both sexes and trigger parallel improvement.

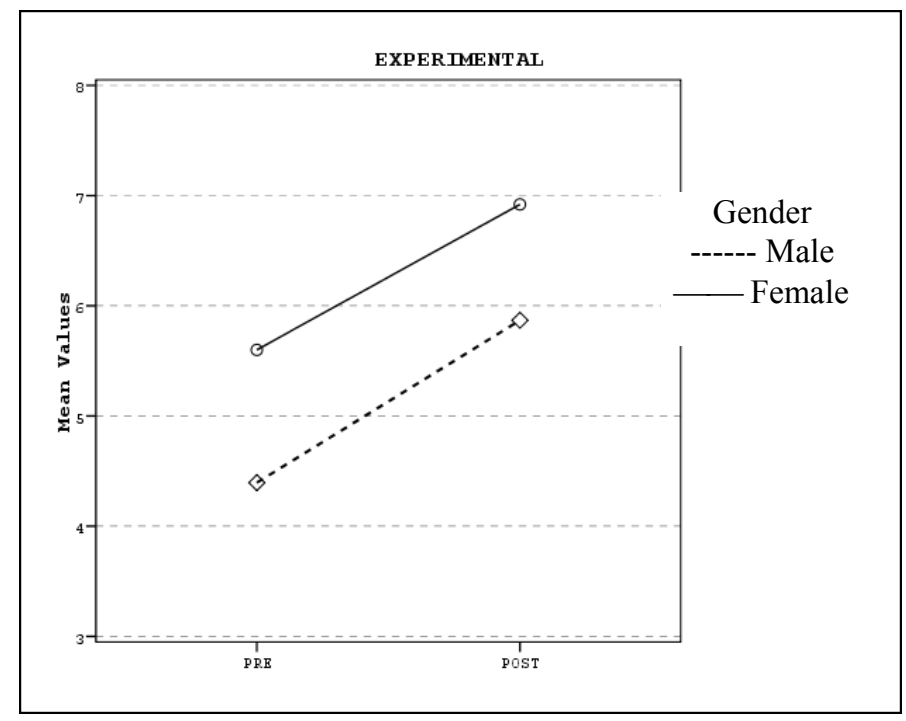

Figure 2. Comparison of pre-and post-scores of the two genders of the experimental group 
In Greece, it is the norm for students to attend private instruction in English which is differentiated into FL schools "frontistiria" or private lessons apart from the tuition they receive at the state schools. This is indicative of the prestige the English language holds in Greek society, as it is considered as a tool for professional and financial advancement. When the control and experimental group of the present study were asked about the attendance of private tuition, an interesting finding emerged as is indicated in table 4, that more members of the control group had received tuition through private lessons where instruction is individualised and covers the students' needs more effectively.

Table 4.

Attendance of English classes at a private language school (frontistirio) or in private lessons at home

\begin{tabular}{|l|c|c|c|c|c|c|}
\hline & \multicolumn{2}{|c|}{ EXPERIMENTAL } & \multicolumn{2}{c|}{ CONTROL } & \multicolumn{2}{c|}{ TOTAL } \\
\cline { 2 - 7 } & $\mathrm{N}$ & $\%$ & $\mathrm{~N}$ & $\%$ & $\mathrm{~N}$ & $\%$ \\
\hline FRONTISTIRIO & 32 & $\mathbf{8 8 . 9}$ & 30 & $\mathbf{7 5 . 0}$ & 62 & 81.6 \\
\hline PRIVATE LESSONS & 3 & $\mathbf{8 . 3}$ & 10 & $\mathbf{2 5 . 0}$ & 13 & 17.1 \\
\hline BOTH & 1 & 2.8 & 0 & 0.0 & 1 & 1.3 \\
\hline
\end{tabular}

$\chi^{2}(2)=4.636, p=0.098$

This finding verified that it was the application of process writing that affected the performance of the experimental group members rather than any other external factors.

\section{Pedagogical Implications}

An attempt will be made in this part to provide certain recommendations concerning the teaching of writing, the salience of cooperation, the formulation of appropriate materials and the effective training of teachers.

\subsection{Stressing the Importance of the Process of Writing}

The following suggestions are provided concerning the application of process writing, rendering, in this way, students into able writers:

1. Students should be trained in the process of writing by being given ample practice with planning, drafting, redrafting after receiving peer or teacher feedback and revising before editing their final product.

2. Devoting time to writing in the classroom is imperative, because students will develop linguistically and cognitively. 


\subsection{Exploiting Collaboration}

One of the most central tenets of process writing is the capitalisation on cooperation:

- Cooperation among the students during writing will engage them in an appealing context, whereby they will actively participate in the learning process and at the same time boost their "interpersonal intelligence" (Gardner, 1983) by interacting meaningfully with other people.

- Moreover, collaboration between the teacher and the students will provide children with input within the Zone of Proximal Development (Vygotsky, 1978) with the assistance from one more knowledgeable than themselves.

\subsection{Maximising the Learning Milieu}

The learning context can be improved in the following aspects:

a) The materials used at state school should be optional rather than preset by the Ministry of Education, giving each teacher the opportunity to select the syllabus which he/she believes is appropriate to the needs of his/her students.

b) If the Ministry selects to assign a book for all schools, they have to hire wellqualified materials writers, who are familiar with the process paradigm, so as to design challenging syllabuses equipped with lessons which will foster the procedure of writing.

c) Teacher trainers ought to be familiarised with the process approach and provide pre- and in-service training to teachers. This will enable teachers to create or choose appropriate supplementary materials to cover the inadequacies of the syllabus.

d) Teachers need to reconsider their role as feedback and reward providers. They should concentrate more on what the students have attained rather than on where they have failed. Their role is redefined as a facilitator relinquishing the one of the omnipotent judge.

e) Should any problems arise while implementing process writing, the teachers ought to be ready to do any necessary adjustments to fit the local context.

\section{Conclusion}

In order to contribute to the need for more research on the efficacy of the process writing approach in the Greek context, the current study explored the extent to which this paradigm facilitated the students of the experimental group of the 
sixth grade of Greek state primary schools to improve their writing capacity in English as compared to the performance of the control group members. It was found that indeed the experimental group participants were aided to outperform their control group counterparts.

Not only did this research investigate the group parameter but it also analysed the dimension of gender, showing that females presented better writings than males substantiating, thus, the second research question on statistically significant terms. On the other hand an interesting finding arose: even though the original assumption was that the girls would respond more positively to the intervention, both sexes of the experimental group displayed similar reaction to the new treatment and managed to benefit from its application. This necessitates further research on the importance of the value and the quality of the employed instruction techniques that will enable both genders to fully develop their potential.

The contributions of the present research are the following:

1. The students realised that writing is not final and predetermined but a dynamic procedure, which follows a cyclical process and can be organised, reorganised and improved.

2. The process writing approach can turn sixth grade learners of the Greek state school into more autonomous, competent users of written discourse in English.

3. Learners in the process classroom are aided to assume more responsibility as writers participating meaningfully in the process of their own learning.

4. Finally, pedagogical and methodological innovations can succeed in the Greek state school if they are carefully designed and applied in classroom.

Finally, further research is proposed in other learning environments, such as secondary schools and tertiary education, in order to validate the efficacy of process writing. 


\section{References}

Akyel, A. and Kamisli, S. 1996. Composing in First and Second Languages: Possible Effects of EFL Writing Instruction. Paper presented at the Balkan Conference on English Language Teaching of the International Association of Teachers of English as a Foreign Language: Instabul, Turkey: 1-31.

Anastasiadou, A. 2003. Improving the Teaching of Writing in the Greek State Primary Schools: Developing Supplementary Writing Materials for the Sixth Form Students. Unpublished MA Thesis, Hellenic Open University: Patras.

Anastasiadou, A. 2010. Implementing the Process Writing Approach in the English Language Classroom: An Innovation for the Development of Young Learners' Writing Skills in the Greek State Primary School. Unpublished PhD Dissertation, Aristotle University of Thessaloniki: Thessaloniki.

Badger, R. and White, G. 2000. A Process Genre Approach to Teaching Writing. ELT Journal 54/2 April: 153-160.

Brookes, A. and Grundy, P. 1990. Writing for Study Purposes. Cambridge: Cambridge University Press.

Byrne, D. 1988. Teaching Writing Skills. London: Longman.

Council of Europe. 2001. Common European Framework for Reference for Language: Learning, Teaching, Assessment. Cambridge: Cambridge University Press.

Dendrinos, B. 2007. KPG Script Rater Guide. Athens: National and Kapodistrian University of Athens, Faculty of English Studies. 
Drepanioti, K. 2009. From Product to Process and Content Writing in Lower Secondary EFL Education: Researching the Issue Experimentally. Unpublished MA Thesis, Hellenic Open University: Patras.

Emig, J. 1971. The Composing Processes of Twelfth Graders. Urbana, Illinois: National Council of Teachers of English.

Gallego de Blibeche, O. 1993. A Comparative Study of the Process versus Product Approach to the Instruction of Writing in Spanish as a Foreign Language. Unpublished doctoral dissertation, Pennsylvania State University: Pennsylvania.

Gardner, H. 1985. Frames of Mind: The Theory of Multiple Intelligences. New York: Basic Books.

Giannakopoulou, A. 2002. Children's Writing in the Early Primary Years: a Processbased Approach to Teaching L2 Writing. Unpublished master's thesis, Hellenic Open University: Patras.

Gomez, R. Jr., Parker, R., Lara-Alecio, R. and Gomez, L. 1996. Process versus Product Writing with Limited English Proficiency Students. The Bilingual Research Journal 20/2: 209-233.

Grabe, W. and Kaplan, R. 1996. Theory and Practice of Writing. London: Longman.

Hammouda, D.D. 2005. Adapting Process-oriented Writing Approaches to Crosscultural Contexts: the Case of French University Students. 3rd Conference of the European Association for the Teaching of Academic Writing: Athens.

Harbord, J. 2005. Developing Writing Skills: The Role of Models. 3rd Conference of the European Association for the Teaching of Academic Writing: Athens.

Hasiotou, V. 2005. Writing and the EFL Learner: a Case Study of Teaching Process Writing to Greek Junior High School Students. Unpublished master's thesis, Hellenic Open University: Patras.

Hedge, T. 1988. Writing. Oxford: Oxford University Press.

Horowitz, D. 1986. Process not Product: Less than Meets the Eye. TESOL Quarterly, 20: 141-144.

Hyland, K. 2002. Teaching and Researching Writing. Harlow: Longman. 
Kern, R. and Schultz, ]. 1992. The Effects of Composition Instruction on Intermediate Level French Students' Writing Performance: Some Preliminary Findings. Modern Language Journal 76: 1-13.

KET. 1998. Cambridge: University of Cambridge.

KET. 2006. Cambridge: University of Cambridge.

Koutsogeorgopoulou, F. 2007. The Teaching of Process Writing and the Provision of Feedback in the 3rd Grade of Junior High School: Teacher Awareness. Unpublished master's thesis, Hellenic Open University: Patras.

Kroll, B. 1990. What Does Time Buy? ESL Student Performance on Home versus Class Compositions. In Kroll, B. (ed) Second Language Writing: Research Insights from the Classroom. Cambridge: Cambridge University Press.

Kroll, B. 1990. Second Language Writing: Research Insights from the Classroom. Cambridge: Cambridge University Press.

Muchnick-Goldber, A. and Wolfe, D.E. 1982. Attitudes and Motivations of American Students of Spanish. The Canadian Modern Language Review 38: 262281.

Nikolaki, A. 2005. Implementation of a Computer-Assisted Process-Writing Framework in the State Primary School Curriculum. Unpublished Master's thesis, Hellenic Open University: Patras.

Nikolaou, A. 2004. Attitudes and Motivation of Greek Upper Secondary School Pupils for Learning English As A Foreign Language. Unpublished doctoral dissertation, University of Birmingham: Birmingham.

O' Brien, T. 1999. The Teaching of Writing Skills in a Second/ Foreign Language. Vol. 3, 4. Patras: Hellenic Open University.

Pincas, A. 1962. Teaching English Writing. London: The Macmillan Press Limited.

Quick Placement Test. 2001. Oxford: Oxford University Press.

Raimes, A. 1983. Techniques in Teaching Writing. Oxford: Oxford University Press.

Reid, J. 1984a. Comments on Vivian Zamel's 'The Composing Process of Advanced ESL students: Six Case Studies' TESOL Quarterly, 18: 149-159. 
Reid, J. 1984b. The Radical Outliner and the Radical Brainstormer: A Perspective on Composing Processes. TESOL Quarterly, 18: 529-533.

Sepyrgioti, M., Papapetrou, M., Karidi, M., Kosovitsa, C. 1999. Fun Way English 3. Athens: $\mathrm{OE} \triangle \mathrm{B}$.

Simou, T. 2006. A Process Approach to Writing Using Word Processing to Affect Young EFL Learners' Writing Behaviour: a Proposal. Unpublished master's thesis, Hellenic Open University: Patras.

Sung, H. and Padilla, A.M. 1998. Student Motivation, Parental Attitudes, and Involvement in the Learning of Asian Languages in Elementary and Secondary Schools. The Modern Language Journal 82/2: 205-216.

Takou, E. 2007. The Word Processor as an Aid for Integrating Process Writing in the Young Learner EFL Classroom. Unpublished master's thesis, Hellenic Open University: Patras.

Taylor, B. 1981. Teaching Composition to Low Level ESL Students. TESOL Quarterly, 10: 309-313.

Tribble, C. 1996. Writing. Oxford: Oxford University Press.

Vygotsky, L. 1978. Mind in Society. Cambridge, Massachusetts: Harvard University Press.

White, R. and Arndt, V. 1991. Process Writing. Harlow: Longman.

Zamel, V. 1982. Writing: the Process of Discovering Meaning. TESOL Quarterly, 16: 195-209. 


\section{Appendix A}

\section{Marking scheme (Anastasiadou, 2010)}

\author{
All four parts of message clearly \\ communicated. Good organisation of ideas. \\ Fully coherent text. Simple connectors \\ 'and', 'but', 'because' have been used. No \\ effort is required by reader.
}

All four parts of message communicated. Good organisation of ideas. Coherent text. Simple and mostly correct connectors used. No effort is required by reader.

All four parts of message attempted or three parts of message are clearly communicated but one is unattempted. Quite good organisation of ideas. Coherent text. Simple and mostly correct linking words used. Minor effort required by reader.

Only three parts of message attempted or two parts of message are clearly communicated but two are unattempted. Quite good organisation of ideas. Fairly coherent text. A few incorrect cohesive devices. Minor effort required by reader.

Only two parts of message are adequately communicated. Fairly good organisation of ideas. Cohesion devices are sometimes incorrect or inappropriate. A little effort may be required by reader.

Only two parts of message communicated. Somewhat disorganised ideas but the text is generally coherent. Frequently incorrect and inappropriate cohesive devices. A little effort is required by reader.

Only one part of message communicated. Poor sequencing of ideas. The text is mostly incoherent and the cohesion is very problematic. Considerable effort may be required by reader.

Question unsuccessfully attempted. Very poor ordering of ideas. The text is mostly incoherent and the cohesion is seriously problematic. Considerable effort is required by reader.

Question unattempted. The reader must rely on own interpretation.

No response or scattered words.

Minor spelling and punctuation errors which do not impede communication of meaning. Uses simple grammatical structures correctly most of the times. Use of simple vocabulary that is in his/her range.

Few spelling and punctuation errors which do not distort meaning. Uses simple grammatical structures correctly but occasionally mixes tenses and forgets agreement. Occasionally uses inappropriate words.

Some spelling and punctuation errors which do not affect meaning seriously. Uses simple grammatical structures but often mixes tenses and forgets agreement. Repetition of vocabulary.

Some incorrect spelling and punctuation and simple grammatical structures with a few errors which do not interfere with intelligibility seriously. Some incorrect words.

Some incorrect spelling and punctuation. A few problematic grammatical structures. Some incorrect vocabulary. These problems partly affect intelligibility.

Frequent spelling and punctuation errors which affect interpretation of meaning. Frequent errors in grammar. Limited vocabulary.

Spelling, punctuation, grammar and vocabulary errors are frequent and parts of the text are sometimes difficult to understand.

Spelling, punctuation, grammar and vocabulary errors are very frequent and a few parts of the text are unintelligible.

Spelling, punctuation, grammar and vocabulary errors are so severe that intelligibility is almost impossible. Intelligibility is impossible. 


\section{Appendix B}

\section{Writing test (entry)}

(Based on an idea by Anastasiadou, A. (2003)

You are Dimitris. You live in Katerini. This is the beginning of the school year. Send a letter to your cousin George who lives in Boston with his family.

Say: How you are and how you feel about the beginning of the school year.

Where you went for holidays and what you did there.

Ask: About his summer holidays.

Start and finish your letter appropriately and at the end of your letter add something you have forgotten.

Write up to 100 words.

\section{Writing test (exit)}

You are Dimitris. You live in Katerini. Your cousin George, who does not speak Greek well, lives in Boston with his family. This is the end of the school year. Send a letter to your cousin George.

Write: How you are and how you feel about the end of the school year.

Where you will go for holidays and what you will do there.

Ask: Ask his plans about his summer holidays.

Start and finish your letter appropriately and at the end of your letter add something you have forgotten.

Write up to 100 words. 
Major Trends in Theoretical and Applied Linguistics 